\title{
Late Complications after Alcohol Septal Ablation in a Patient with Hypertrophic Obstructive Cardiomyopathy
}

\author{
Raluca Șoșdean ${ }^{1,2,3, *}$, Laurențiu Pașcalău ${ }^{1}$, Monica Mircea ${ }^{1}$, Loredana Ionică ${ }^{1,3}$, \\ Petru Baneu ${ }^{1}$, Alexandru Pescariu ${ }^{1,2}$, Adrian Sturza ${ }^{3,4}$, Cristian Mornoș ${ }^{1,2}$ and \\ Sorin Pescariu ${ }^{1,2}$

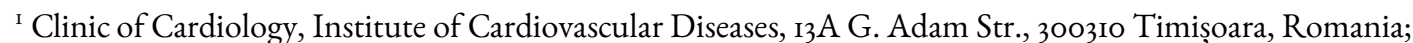 \\ pascalaulaurentiu@yahoo.com (L.P.); mircea.monica@yahoo.ro(M.M.); ionica.lori@yahoo.com (L.I.); \\ petru.baneu@gmail.com (P.B.); alex.pescariu@yahoo.com (A.P.); mornoscristi@yahoo.com (C.M.); \\ sorinpescariu@yahoo.com (S.P.) \\ ${ }^{2}$ Department of Cardiology (VI), Faculty of Medicine, "Victor Babeș” University of Medicine and Pharmacy, 2 \\ Eftimie Murgu Sq., 30004I Timișoara, Romania \\ ${ }_{3}^{3}$ Center for Translational Research and Systems Medicine, Faculty of Medicine, "Victor Babeș” University of \\ Medicine and Pharmacy, 2 Eftimie Murgu Sq., 30004I Timișoara, Romania; sturza.adrian@umft.ro \\ ${ }^{4}$ Department of Functional Sciences-Pathophysiology, Faculty of Medicine, "Victor Babeș” University of Medicine \\ and Pharmacy, 2 Eftimie Murgu Sq., 30004I Timișoara, Romania \\ *Correspondence: sosdean.raluca@umft.ro
}

Submitted: Io December 2020; Accepted: 19 January 202I; Published: 25 January 202I

\begin{abstract}
I) Background: Complete atrioventricular block is a well-known complication of alcohol ablation as a septal reduction therapy, implemented in selected patients with hypertrophic obstructive cardiomyopathy (HOCM). It usually occurs during or immediately after the intervention. Rare cases of late complete atrioventricular block (CAVB) have been reported, but data are still scarce in the literature regarding this issue. (2) Case report: We report the case of a 70-year-old male patient, with mild aortic stenosis, but with a significantly degenerated valve and perivalvular tissue, and a nonspecific intraventricular conduction delay, which developed intensely symptomatic CAVB, four months after alcohol septal ablation (ASA) for HOCM, along with left ventricular pressure gradient recurrence. Both problems were resolved by implantation of a dual chamber pacemaker, with pacing optimization to a short atrioventricular interval, along with a maximal tolerated betablocker therapy. With the description of the patient's treatment and evolution in comparison with other reports and studies, this case report highlights the fact that a close clinical, electrical and echocardiographic surveillance is warranted for this kind of patients, as late CAVB may be a life-threatening complication. Previous electrical conduction problems and degenerated aortic valve and perivalvular tissue may be predisposed for this type of complication, independent of betablocker therapy. This treatment has several other beneficial effects and thus it should not be interrupted after the procedure.
\end{abstract}

Keywords: obstructive hypertrophic cardiomyopathy; alcohol septal ablation; abnormal electrical conduction; late complete AV block; LVOT pressure gradient recurrence; dual chamber pacemaker implantation

How to cite: Şoșdean, R.; Pașcalău, L.; Mircea, M.; Ionică, L.; Baneu, P.; Pescariu, A.; Sturza, A.; Mornos,, C.; Pescariu, S. Late Complications after Alcohol Septal Ablation in a Patient with Hypertrophic Obstructive Cardiomyopathy. Timisoara Med. 2020, 2020(2), 3; doi:I0.35995/tmj20200203. 


\section{Introduction}

As septal reduction therapies, both alcohol septal ablation (ASA) and surgical septal myectomy (SSM) proved to be effective in left ventricular outflow tract (LVOT) pressure gradient reduction and functional status improvement, with a similar low mortality rate of less than $\mathrm{I} \%[\mathrm{I}-5]$. The latest studies show that both techniques significantly reduce the mortality rate in obstructive hypertrophic cardiomyopathy patients, even though the septal scar induced by alcohol ablation could have acted like an arrhythmogenic substrate [5-9]. As compared to the SSM though, ASA seems to have a higher risk of residual pressure gradients in the LVOT $[\mathrm{I}-3]$.

The choice between the two techniques is made by a thorough imagistic evaluation of the interventricular septum and mitral apparatus morphology and function with the implication of a multidisciplinary team. ASA is usually recommended to be performed in experienced hospitals, in patients with persistent symptomatology under maximal medical therapy, with a hemodynamically significant LVOT pressure gradient (rest or provoked), patients that lack any other pathologies that could or should be surgically treated (i.e., severe mitral regurgitation that is not secondary to the systolic anterior movement of the anterior mitral leaflet) $[\mathrm{I}]$. Being an interventional technique and thus avoiding open heart surgery, ASA is used lately 5 to Io times more often than SSM in several European countries [5,Io]. Many intraoperative complications (i.e., prevention of inducing an extended myocardial infarction, prevention of inducing papillary muscle ischemia and necrosis with consecutive acute severe mitral regurgitation, secondary to a communication between the target septal branch and the right coronary artery, etc.) have been prevented lately by a thorough imagistic investigation of the patient prior to the intervention and by a close guidance of the intervention by using contrast echocardiography $[4,5]$.

As regarding the benign complications that interfere with impulse conduction, usually SAA induces right bundle branch block in a very high percentage of patients $(\sim 80 \%)$, secondary to ischemia and necrosis of the right bundle branch as compared to SSM, that usually induces left bundle branch block [5]. A more serious problem is the complete atrioventricular block induced during or immediately after the intervention. This might have an ischemic or inflammatory etiology, due to the proximity of the atrioventricular (AV) node to the infarcted area. The complication is encountered in $9-21 \%$ or even more (up to $50 \%$ in some studies) of ASA patients and is related to, among other factors, the quantity of injected alcohol and previous abnormal electrical conduction $[\mathrm{I}, 5]$. Treatment consists of the implantation of a dual chamber pacemaker for persistent AV block, which is encountered in 5-10\% of the patients. Rare cases of late complete AV block occurrence after ASA were described [5,Io]. This situation is much more serious as the patients are no longer hospitalized and thus, it might not be possible to solve the problem immediately/in time. Data are scarce in the literature regarding this issue.

We present the case of a patient that underwent ASA for hypertrophic obstructive cardiomyopathy (HOCM), and developed complete AV block four months later, describing his evolution and management.

\section{Case Report}

The 70-year-old male patient, with a history of colorectal cancer curatively operated on in 2012, with type 2 diabetes mellitus, underwent interventional septal reduction therapy by alcohol ablation of the first septal artery for hypertrophic obstructive cardiomyopathy, four months before the current admission. The intervention was performed with thorough contrast echocardiography guidance that showed the target vessel territory to be limited to the basal part of the interventricular septum, without contrast intake in other parts of the left ventricle, thus excluding any communication with other coronary arteries. A volume of 
$3.5 \mathrm{~mL}$ alcohol was used for the procedure. The results were good, without complications, except for a transient complete AV block, for which a temporary pacemaker lead was already implanted, according to the protocol. The conduction problem resolved spontaneously in the first $24 \mathrm{~h}$ after the procedure and thus the temporary pacing was removed, leaving sinus rhythm with RBBB on the resting electrocardiogram (ECG), with signs of interventricular septum basal myocardial infarction (Figure I).

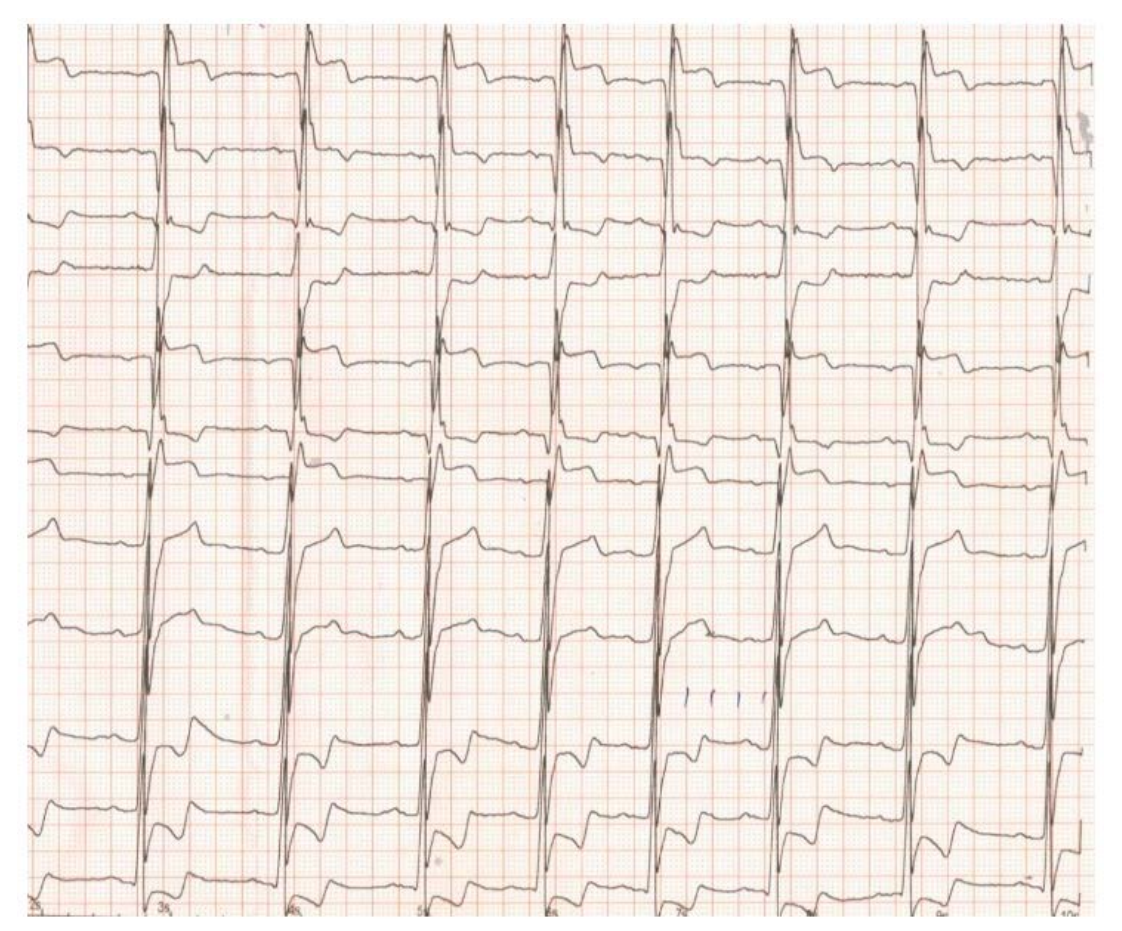

Figure 1. Twelve lead resting ECG post-alcohol septal ablation (ASA). See text for details.

We must mention here that the patient had a nonspecific intraventricular conduction delay on the ECG before the intervention, with no history of AV block. Echocardiography showed a significant LVOT pressure gradient reduction from $58 \mathrm{mmHg}$ to $18 \mathrm{mmHg}$ (beyond the obstruction limit), a residual mild degenerative mitral regurgitation, mild degenerative aortic stenosis and regurgitation (already diagnosed 2 years ago), along with a significant improvement in symptomatology. The clinical and echocardiographic results persisted at the one month follow-up, as well as the $24 \mathrm{~h}$ ECG Holter monitoring findings that showed no sinus pauses, no AV block, with a low number of isolated supraventricular and ventricular premature beats. Betablocker therapy was continued. Given the aortic valve anomalies, a differential diagnosis of the patient's LV asymmetric hypertrophy was conducted before ASA. The LV asymmetric hypertrophy is described in a minority of cases, with severe aortic stenosis and and/or in association with arterial hypertension (AHT), which was not the case of our patient (mild aortic stenosis, no history of AHT) [II].

The patient is admitted now for intense fatigue, dizziness with one episode of syncope, intense dyspnea, all starting about $36 \mathrm{~h}$ before presentation. Home heart rate measurement affirmatively pointed to a value of $30-35$ beats/minute, for which the patient interrupted the betablocker, with no improvement, but the worsening of clinical status.

The ECG at admission showed complete AV block with a heart rate of 40 beats/minute (Figure 2), and clinically, the patient was in acute pulmonary oedema. Echocardiography revealed a LVOT pressure gradient 
increase to $8 \mathrm{ommHg}$, with an intense systolic contraction of the left ventricle (left ventricular ejection fraction of $75 \%$ ) in the situation of sudden betablocker interruption. As betablocker could not be reintroduced with complete AV block, in this emergency situation, a temporary pacemaker was implanted and set to pace at a heart rate of 50 beats/minute to allow an appropriate LV diastolic filling. The betablocker was reintroduced in the highest tolerated dose and diuretic therapy was carefully administered to help relief the pulmonary pressures and stasis, but also to prevent patient dehydration. The pulmonary oedema resolved, and the patient was stable.

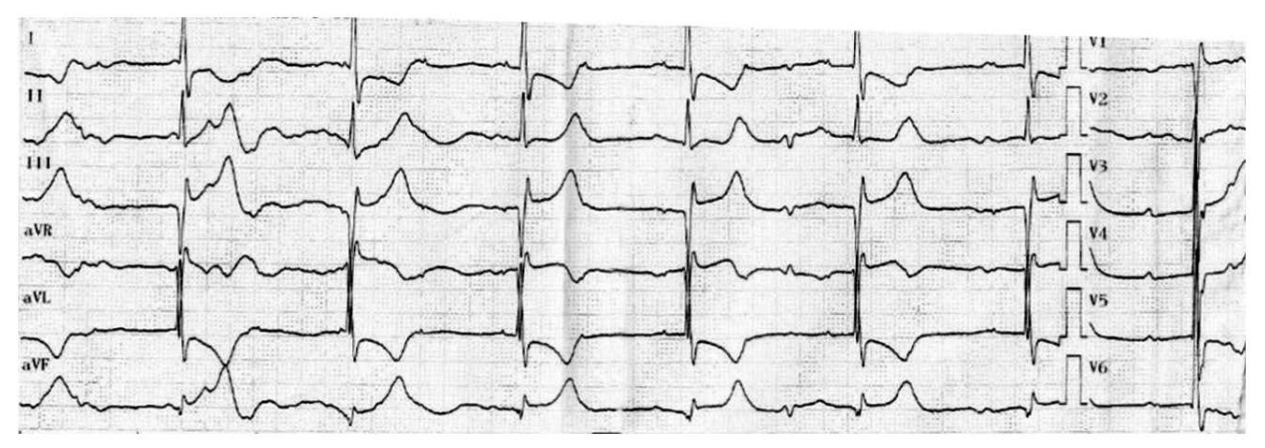

Figure 2. ECG with complete AV block, four months after ASA.

The next step was to implant a dual chamber pacemaker set to pace in the DDDR mode with 50 beats/minute as the lowest heart rate and 130 beats/minute as the highest heart rate (Figure 3). With a sensed/paced AV interval of $120 / 150 \mathrm{~ms}$ and maximal tolerated betablocker therapy, the LVOT pressure gradient measured by echocardiography one day after the implantation procedure was $42 \mathrm{mmHg}$. The AV interval was echocardiographically optimized to a short value-sensed/-paced of 80/100 ms with a drop in the LVOT pressure gradient to $25 \mathrm{mmHg}$. The patient was discharged after 2 days, with a significantly improved clinical status.

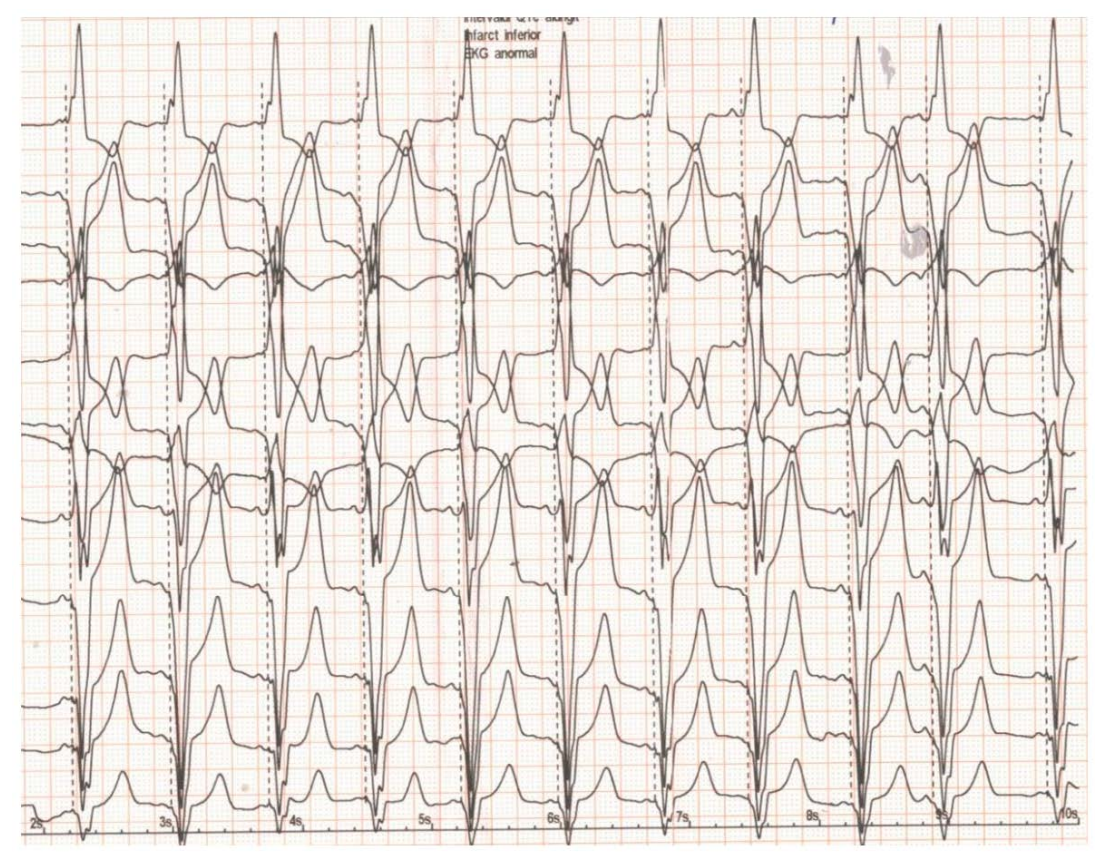

Figure 3. ECG after implantation of a dual chamber pacemaker. See text for details. 


\section{Discussions}

Our patient experienced a delayed complete atrioventricular block four months after alcohol septal ablation for hypertrophic obstructive cardiomyopathy. This entity, by definition, occurs after more than $48-36 \mathrm{~h}$ after the intervention, and is encountered in a significantly lower percent compared to the acute AV block [4,IO]. Literature reports an incidence of up to 10\%, but it may also be an underdiagnosed pathology, as some patients might not reach medical care anymore [Io].

Veselka et al. reported that one-third of the patients developed complete AV block after the procedure was completed, but before the fifth day [12]. The mechanisms underlying acute AV block during or immediately after the intervention of alcohol septal ablation consist in ischemia/necrosis of the AV node because of the inclusion of this structure in the infarcted area, or in inflammation/oedema of the area surrounding the infarction, also including the AV node ( half of the patients) [4]. It is normally encountered in the first $48 \mathrm{~h}$ after the procedure, and in case of an inflammatory etiology, it is reversible in I-2 days, rarely after a longer period (a maximum of $\mathrm{I} 3$ days was reported). As concerning the delayed occurrence of the AV block, the suggested mechanisms are the left ventricular remodeling which takes place during the following several months after the procedure, as demonstrated by cardiac magnetic resonance, and the postinfarction scar remodeling and potential expansion by subsequent alteration of the periinfarct tissue, later also including the AV node. Some autopsy studies proved a persistent collagen formation during up to 90 days after myocardial infarction, which was seen both in rat and in human [ro]. The complication may occur in patients without acute AV block as well as in patients with recovered acute conduction abnormality [4].

Several authors reported a number of cases of delayed AV block, most of them within the first 7-8 days after the intervention. Wykrzykowska et al. reported a case of delayed AV block after $96 \mathrm{~h}$ of the intervention, without any acute postprocedural conduction problem and/or other risk factors [13]. Poyet et al. reported a patient that developed the same problem after 8 days of the procedure, and Boekstegers et al. described 2 cases 7 days after the procedure, but with several risk factors for such a complication [14,15]. Schuler et al., on the other hand, conducted a study in which they followed-up for $3.2 \pm 2.3$ years, a number of $\mathrm{I}_{42} \mathrm{OHCM}$ patients that underwent 168 ASA procedures [ro]. They found an incidence of delayed AV block of $8.9 \%$ in these patients, from which 3.6\% occurred after hospital discharge, between $48 \mathrm{~h}$ and 3 years after the intervention, as experienced by our patient. They suggest that this is an important finding, as it may increase long term mortality after SAA.

In recent years, several factors have been indicated to increase the risk of AV block after ASA. Baseline left bundle branch block was one of them, as ASA supplementary induces right bundle branch block, thus resulting in complete atrioventricular block (CAVB). Some authors even suggest elective pacemaker implantation in patients with left bundle branch block undergoing ASA. Moreover, baseline or post-procedural first degree AV block, intraprocedural complete AV block and new intraventricular conduction defect were described [4]. Faber et al. included baseline ECG parameters, like a PR interval longer than $160 \mathrm{~ms}$, heart rate lower than 50 beats/minute, an LVOT pressure gradient of over $70 \mathrm{mmHg}$, periinterventional myocardial enzyme kinetics and conduction abnormalities in a scoring system regarding permanent AV block risk [16]. Other factors, such as age of over 55, female gender, lack of intervention guidance by contrast echocardiography, bolus alcohol administration, use of a high quantity of alcohol (more than $4 \mathrm{~mL}$ ) and ablation of more than one septal branch, have been also proposed [17,18]. Schuler et al. on the other hand, in their more recent study, demonstrated that after adjustment, only multiple ASA procedures and a significantly high preprocedural resting LVOT pressure gradient were significant predictors for complete AV block [io]. 
Our patient had only one ASA procedure, implying a single septal branch, with a preprocedural pressure gradient of $58 \mathrm{mmHg}$, but with a nonspecific intraventricular conduction delay. Moreover, he had a degenerated aortic valve with intense fibrosis of the cusps, ring and surrounding tissue that might have contributed to the alteration of the $\mathrm{AV}$ node function.

Regarding the benefits of ASA, often these are delayed for several month, sometimes months or even more, as the scar remodeling and the reduction in the interventricular septum thickness takes time [5]. In our patient, the benefits were seen immediately after the procedure and were maintained at the one-month follow-up. A recurrence of the LVOT pressure gradient was encountered after four months when he was admitted for the delayed conduction abnormality. The recurrence of the pressure gradient after ASA was described in about 1o\% of cases in the first two years after the procedure. This complication may be explained by an incomplete scar formation, an irregular form of the scar with recovery of the periinfarct tissue-often hibernating myocardium, patchy instead of dense fibrosis, a non-proper location of the scar, an incomplete interventricular septum remodeling or a midventricular migration of the obstruction [19]. In our patient, it is possible for the scarring to have migrated in the direction of the AV node, and also for a part of the hibernating myocardium near the infarction zone to have recovered instead of developing necrosis with subsequent fibrosis and scar. Sudden interruption of the betablocker with a significant increase LV contraction exacerbated the pressure gradient. Interruption of the betablocker lacked any improvement of the conduction abnormality, which proved to be independent of this therapy. As the patient had no history of AV block before ASA, we considered the combined action of possible post ASA remodeling due to intra or infrahissian ischemia and the possible AV node involvement associated with aortic valve fibrosis as the etiology of the AV block. Implantation of a dual chamber pacemaker programmed with a short AV delay, combined with the maximal tolerated betablocker therapy solved the problem in the acute phase. Right ventricular apical pacing with a short AV delay is known as a good method to reduce the LVOT pressure gradient by inducing interventricular septum contraction dyssynchrony $[\mathrm{I}]$, but for some reasons, the studies show that it is less efficient alone, compared with the other two septal reduction therapies [1,19]. On the other hand, many authors recommend the use of the dual chamber pacemaker when one of these techniques fails, instead of repeating the procedure [s].

Lee et al. reported a patient with significant pressure gradient recurrence seven years after the procedure, for which they repeated SAA and implanted a permanent pacemaker, as the procedure resulted in an acute complete AV block [2o]. Velchev et al. reported three patients with symptomatic midventricular obstruction, several months after the procedure of ASA, which was properly resolved by pacemaker implantation [19].

\section{Conclusions}

This case highlights the fact that patients with pre-existing electrical conduction abnormalities and a degenerated aortic valve should be very closely monitored for the possible occurrence of late complete atrioventricular block, as this may be a life-threatening complication. Betablocker therapy should be continued after SAA as, besides the well-known benefits in patients with HCM, it mitigates the extent and symptomatology of LVOT pressure gradient in the rare cases in which it reoccurs. Pacemaker implantation may resolve this complication, besides appropriately treating the complete atrioventricular block.

Author Contributions: Conceptualization, R.S,., L.P.; Writing-Original Draft Preparation, R.S,., M.M., L.I., P.B., A.P.; Writing-Review and Editing, R.S,., C.M., A.S.; Supervision, S.P.

Funding: This research received no external funding. 
Conflicts of Interest: The authors declare no conflict of interest.

\section{References}

I. Elliott, P.M.; Anastasakis, A.; Borger, M.A.; Borggrefe, M.; Cecchi, F.; Charron, P.; Hagege, A.A.; Lafont, A.; Limongelli, G.; Mahrholdt, H.; et al. 20I4 ESC Guidelines on diagnosis and management of hypertrophic cardiomyopathy. The Task Force for the Diagnosis and Management of Hypertrophic Cardiomyopathy of the European Society of Cardiology (ESC). Eur. Heart J. 2014, 35, 2733-2779. [PubMed]

2. Leonardi, R.A.; Kransdorf, E.P.; Simel, D.L.; Wang, A. Meta-analyses of septal reduction therapies for obstructive hypertrophic cardiomyopathy: Comparative rates of overall mortality and sudden cardiac death after treatment. Circ. Cardiovasc. Interv. 2010, 3, 97-IO4. [CrossRef] [PubMed]

3. Agarwal, S.; Tuzcu, E.; Desai, M.Y.; Smedira, N.; Lever, H.M.; Lytle, B.W.; Kapadia, S. Updated Meta-Analysis of Septal Alcohol Ablation Versus Myectomy for Hypertrophic Cardiomyopathy. J. Am. Coll. Cardiol. 2010, 55, 823-834. [CrossRef] [PubMed]

4. Fifer, M.A.; Sigwart, U. Hypertrophic obstructive cardiomyopathy: Alcohol septal ablation. Eur. Heart J. 2011, 32, I059-1064. [CrossRef] [PubMed]

5. Gimeno, J.R.; Tomé, M.T.; McKenna, W.J. Alcohol Septal Ablation in Hypertrophic Cardiomyopathy: An Opportunity to Be Taken. Revista Española de Cardiología 2012, 65, 314-318. [CrossRef] [PubMed]

6. Desai, M.Y.; Smedira, N.G.; Dhillon, A.; Masri, A.; Wazni, O.; Kanj, M.; Sato, K.; Thamilarasan, M.; Thamilarasan, M.; Lever, H.M. Prediction of sudden death risk in obstructive hypertrophic cardiomyopathy: Potential for refinement of current criteria. J. Thorac. Cardiovasc. Surg. 2018, 156, 750-759.e3. [CrossRef] [PubMed]

7. Jensen, M.K.; Prinz, C.; Horstkotte, D.; Van Buuren, F.; Bitter, T.; Faber, L.; Bundgaard, H. Alcohol septal ablation in patients with hypertrophic obstructive cardiomyopathy: Low incidence of sudden cardiac death and reduced risk profile. Heart 2013, 99, IoI2-IoI7. [CrossRef] [PubMed]

8. Tower-Rader, A.; Kramer, C.M.; Neubauer, S.; Nagueh, S.F.; Desai, M.Y. Multimodality Imaging in Hypertrophic Cardiomyopathy for Risk Stratification. Circ. Cardiovasc. Imaging 2020, 13, eoog026. [CrossRef] [PubMed]

9. Veselka, J.; Jensen, M.K.; Liebregts, M.; Januska, J.; Krejci, J.; Bartel, T.; Dabrowski, M.; Hansen, P.R.; Almaas, V.M.; Seggewiss, H.; et al. Long-term clinical outcome after alcohol septal ablation for obstructive hypertrophic cardiomyopathy: Results from the Euro-ASA registry. Eur. Heart J. 2016, 37, 1517-I523. [CrossRef] [PubMed]

Io. Schuller, J.L.; Zipse, M.M.; Krantz, M.J.; Blaker, B.; Salcedo, E.; Groves, B.M.; Messenger, J.C.; Beaty, B.; Sauer, W.H. Incidence and Predictors of Late Complete Heart Block After Alcohol Septal Ablation Treatment of Hypertrophic Obstructive Cardiomyopathy. J. Interv. Cardiol. 2015, 28, 90-97. [CrossRef] [PubMed]

II. Tuseth, N.; Cramariuc, D.; Rieck, Å.E.; Wachtell, K.; Gerdts, E. Asymmetric septal hypertrophy-A marker of hypertension in aortic stenosis (a SEAS substudy). Blood Press. 2010, 19, I40-I44. [CrossRef] [PubMed]

I2. Veselka, J.; Lawrenz, T.; Stellbrink, C.; Zemánek, D.; Branny, M.; Januška, J.; Groch, L.; Dimitrow, P.; Krejci, J.; Dąbrowski, M.; et al. Low Incidence of Procedure-Related Major Adverse Cardiac Events After Alcohol Septal Ablation for Symptomatic Hypertrophic Obstructive Cardiomyopathy. Can. J. Cardiol. 2013, 29, I415-I42I. [CrossRef] [PubMed]

I3. Wykrzykowska, J.J.; Kwaku, K.; Wylie, J.; Manning, W.J.; Josephson, M.E.; Zimetbaum, P.; Laham, R.J. Delayed Occurrence of Unheralded Phase IV Complete Heart Block After Ethanol Septal Ablation for Symmetric Hypertrophic Obstructive Cardiomyopathy. Pacing Clin. Electrophysiol. 2006, 29, 674-678. [CrossRef] [PubMed]

I4. Poyet, R.; Quilici, J.; Cuisset, T.; Bali, L.; Ansaldi, S.; Prévost, S.; Habib, G.; Bonnet, J.-L. Delayed occurrence of complete heart block after ethanol septal ablation for hypertrophic obstructive cardiomyopathy. Int. J. Cardiol. 2011, 147, e32-e34. [CrossRef] [PubMed]

I5. Boekstegers, F.; Steinbigler, P.; Molnar, A. Pressure-guided non-surgical myocardial reduction induced by small septal infarctions in hypertrophic obstructive cardiomyopathy. J. Am. Coll. Cardiol. 2001, 38, 846-853. [CrossRef]

I6. Faber, L.; Welge, D.; Fassbender, D.; Schmidt, H.K.; Horstkotte, D.; Seggewiss, H. Percutaneous septal ablation for symptomatic hypertrophic obstructive cardiomyopathy: Managing the risk of procedure-related AV conduction disturbances. Int. J. Cardiol. 2007, 119, 163-167. [CrossRef] [PubMed]

17. Chang, S.M.; Nagueh, S.F.; Spencer, W.H., III; Lakkis, N.M. Complete heart block: Determinants and clinical impact in patients with hypertrophic obstructive cardiomyopathy undergoing nonsurgical septal reduction therapy. J. Am. Coll. Cardiol. 2003, 42, 296-300. [CrossRef]

I8. Chen, A.A.; Palacios, I.F.; Mela, T.; Yoerger, D.M.; Picard, M.H.; Vlahakes, G.; Lowry, P.A.; Fifer, M.A. Acute Predictors of Subacute Complete Heart Block After Alcohol Septal Ablation for Obstructive Hypertrophic Cardiomyopathy. Am. J. Cardiol. 2006, 97, 264-269. [CrossRef] [PubMed] 
19. Velchev, V.; Postadzhiyan, A.; Hazarbasanov, D.; Finkov, B. Permanent Pacing in Patients with Recurrence of Symptoms and Relapse of Left Ventricular Obstruction at Midcavity Level after Alcohol Septal Ablation. Int. J. Vasc. Med. 2012, 2012, 75750I. [CrossRef] [PubMed]

20. Lee, J.M.; Moon, J.C.; Pennell, D.J.; Sigwart, U.; Clague, J.R. Late recurrence of outflow tract obstruction seven years after septal ablation in hypertrophic cardiomyopathy. Int. J. Cardiol. 2005, 100, 34I-342. [CrossRef] [PubMed]

(C) 202I Copyright by the author. Licensed as an open access article using a CC BY 4.0 license.

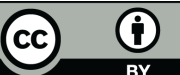

